\title{
Structural Modifications of Nanostructured Cubic CdS Thin-Films due $\mathrm{Cu}^{2+}$ Doping
}

A. Flores-Pacheco ${ }^{1}$, J.I. Contreras-Rascón ${ }^{1}$, R.C. Carrillo-Torres ${ }^{1}$, Paz del Angel-Vicente ${ }^{2}$, A. R. RosasBurgos $^{1}$, R. Sánchez-Zeferino ${ }^{1}$, M.E. Álvarez-Ramos ${ }^{1}$

1. Posgrado en Nanotecnología, Departamento de Física, Universidad de Sonora, Apdo. Postal 1626, C.P. 83000, Hermosillo, Sonora, México.

2. Instituto Mexicano del Petróleo, Dirección de Investigación y Posgrado, Eje Central L. Cárdenas 152, C.P. 07730, Ciudad de México.

The development of II-VI semiconductor nanocomposites doped with metallic ions has gained a lot of attention in different investigation groups given the possibilities of modification of the structural, optical and electrical properties, thanks to the quantum confinement effect [1]. Particularly, using the copper ion $\mathrm{Cu}^{2+}$, remarkable changes in the optical properties of the nanocomposite were noticed [2].

The undoped CdS thin-film was obtained using the chemical bath deposition (CBD) technique, with a constant temperature of $60^{\circ} \mathrm{C}$ without special atmosphere, aqueous solutions of $\mathrm{CdCl}_{2}(0.01 \mathrm{M}, 20 \mathrm{~mL})$ as $\mathrm{Cd}^{2+}$ ions precursor, $\mathrm{NaOH}(0.05 \mathrm{M}, 10 \mathrm{~mL}), \mathrm{NH}_{4} \mathrm{NO}_{3}(0.5 \mathrm{M}, 15 \mathrm{~mL})$ as complexing agent and $\mathrm{SC}\left(\mathrm{NH}_{2}\right)_{2}$ as $\mathrm{S}^{2-}$ ions precursor. Deposition of the thin-films was performed in a recirculating bath. The $\mathrm{Cu}$-doped $(\mathrm{CdS}: \mathrm{Cu})$ nanocomposite was obtained by the addition of the metallic ion $\mathrm{Cu}^{2+}$ Precursor $\mathrm{Cu}\left(\mathrm{NO}_{3}\right)_{2}$ before the complexing reaction.

The SEM micrographs of both samples illustrated in Fig.1a and $1 \mathrm{~b}$ allows qualitative comparison of the particle cluster sizes and densities, showing smaller sizes and higher densities in the doped sample $(\mathrm{CdS}: \mathrm{Cu})$ as shown in Fig. $1 \mathrm{~b}$.

The high resolution XPS superficial analysis of the CdS matrix shows a strong, symmetrical and clean signal of cadmium $3 \mathrm{~d}$ doublet $3 \mathrm{~d}_{3 / 2}(411.7 \mathrm{eV})$ and $3 \mathrm{~d}_{5 / 2}(404.95 \mathrm{eV})$, who has a slight widening illustrated in Fig. 1c, typical of the CdS II-VI binary [3]. The XPS spectra of the $2 p$ doublet of sulfur shown in Fig. 1d shows a chemical shift of $2.4 \mathrm{eV}$ to lesser binding energies from elemental sulfur [4] with the photoelectron peaks of $2 \mathrm{p}_{1 / 2}(162.8 \mathrm{eV})$ and $2 \mathrm{p}_{3 / 2}(161.6 \mathrm{eV})$, also characteristic of cadmium sulfide. The copper ions were found in the surface of the $\mathrm{CdS}: \mathrm{Cu}$ film, as possible $\mathrm{CuS}$ compounds with a $2 p$ doublet with binding energies $2 p_{1 / 2}(913.2 \mathrm{eV})$ and 2 $p_{3 / 2}(933.2 \mathrm{eV})[5]$ (Fig. 1e).

The monocrystalline nature of the undoped CdS thin film can be observed in the TEM micrograph shown in Fig. 2a with an interplanar distance of 3.35 Angstrom associated by Bragg's law with the angular position $2 \theta$ of the (111) CdS cubic phase. A typical particle diameter of around $5.87 \mathrm{~nm}$ was measured. The effects of doping are clear in the micrograph of the $\mathrm{CdS}: \mathrm{Cu}$ sample shown in Fig. 2b, where the quantum confinement is evident, due the reduction of the particle diameter to an average size of $4.76 \mathrm{~nm}$. The change to a polycrystalline structure of the $\mathrm{CdS}: \mathrm{Cu}$ sample is confirmed in the micrograph in Fig 2b, with different crystalline domains that are clearly visible.

The results presented in the present work highlight the viability of the CBD technique for structural modification of CdS thin films via doping [6]. 
References:

[1] R Koole et al. in "Nanoparticles", ed. C de Mello Donegá, (Springer-Verlag, Berlin) p.13.

[2] M Muthusamy and S Muthukumaran, Optik - International Journal for Light and Electron Optics 126 (2015), p. 5200.

[3] Thermo-Fischer-Scientific, "XPS Reference Table of Elements." [Online]. Available:

http://xpssimplified.com/elements/cadmium.php. [Accessed: 20-Nov-2016].

[4] J F Moulder, W F Stickle, P E Sobol, and K D Bomben, "Handbook of X-ray Photoelectron Spectroscopy", Second edition. (Perkin-Elmer Corporation Physical Electronics Division, Eden Prairie) 1992.

[5] V Krylova and M Andruleviçius, International Journal of Photoenergy 2009 (2009), id. 304308. [6] The authors acknowledge funding from Consejo Nacional de Ciencia y Tecnología (CONACyT) project number 255791-INFR-2015
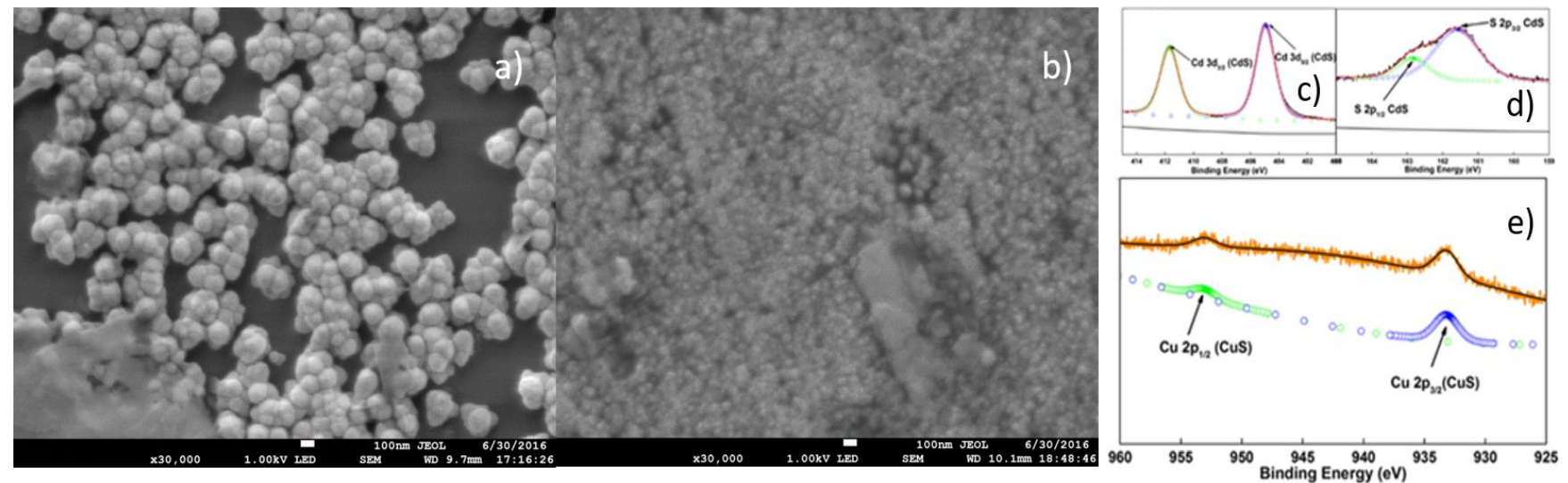

Figure 1. SEM micrographs of a) $\mathrm{CdS}$ and b) $\mathrm{CdS}: \mathrm{Cu}$ thin-films. High resolution photoelectron spectra of the binding energy ranges of c) cadmium in $\mathrm{CdS}$ d) sulfur in $\mathrm{CdS}$ and d) copper in $\mathrm{CdS}: \mathrm{Cu}$

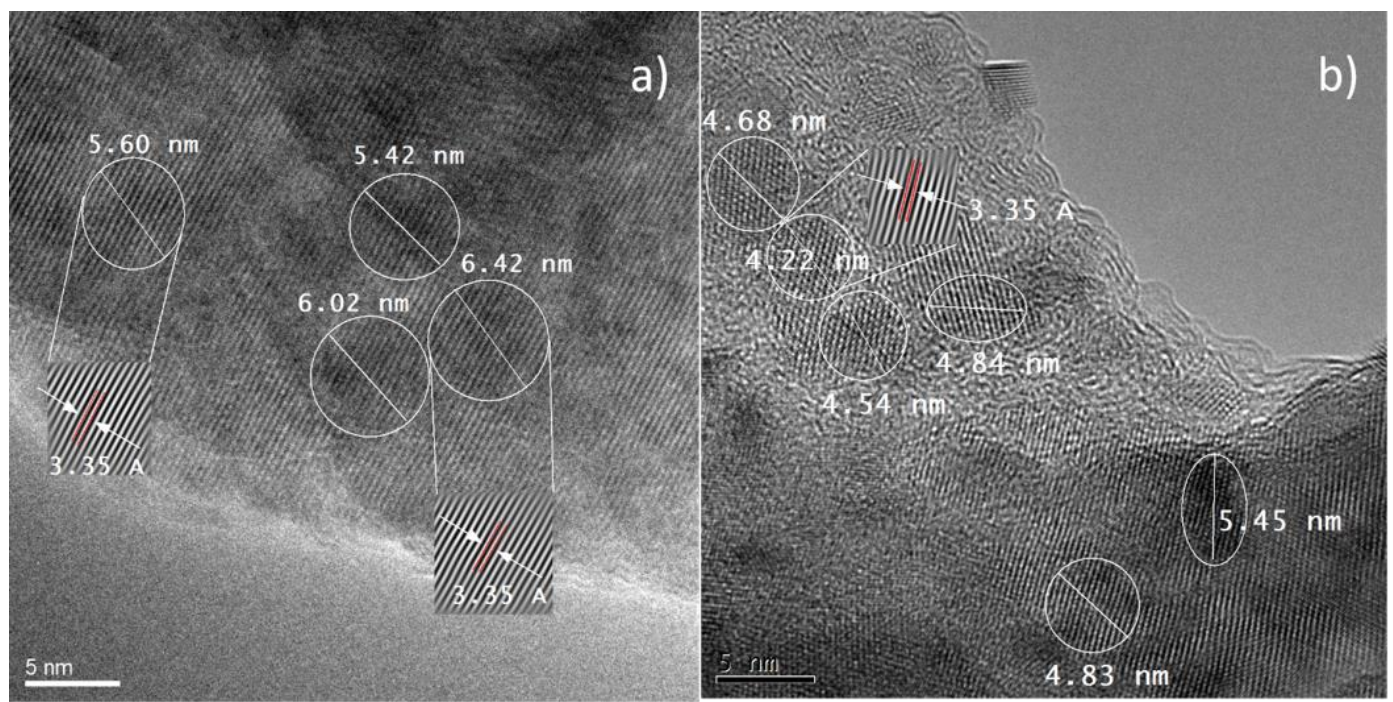

Figure 2. TEM micrographs of a) $\mathrm{CdS}$ and b) $\mathrm{CdS}: \mathrm{Cu}$ samples. 